\begin{tabular}{c} 
Volume and Issues Obtainable at Center for Sustainability Research and Consultancy \\
Journal of Business and Social Review in Emerging Economies \\
ISSN: 2519-089X (E): 2519-0326 \\
Volume 4: Issue 1June 2018 \\
CSRᄃ \\
Journal homepage: $\underline{\text { www.publishing.globalcsrc.org/jbsee }}$ \\
\hline
\end{tabular}

\title{
Theories of Grandparental Stress
}

\author{
${ }^{1}$ Thamilselvi Pandialagappan, ${ }^{2}$ Rahimah Ibrahim \\ ${ }^{1}$ Malaysian Research Institute on Ageing, Universiti Putra Malaysia. tselvi57@yahoo.com \\ ${ }^{2}$ Faculty of Human Ecology, Universiti Putra Malaysia. imahibrahim@gmail.com
}

\section{ARTICLE DETAILS}

\section{History}

Revised format: May 2018

Available Online: June 2018

\section{Keywords}

Grandparental Stress, Factors,

Theory

JEL Classification:

J12, J19

\begin{abstract}
Many grandparents today have the responsibility of caring for their grandchildren. Clearly, grandparenting has become a complex, diversified role within families. As the number of grandparent-headed households continues to increase in society, so do their stressors. Although it is not a new phenomenon, interest in examining grandparental stress is relatively new. The focus of this paper is to provide an overview of theories and factors influencing grandparental stress. The paper briefly reviews theories to explain causes of grandparental stress. Based on the reviewed theories, it can be concluded that grandparental stress is a multifactorial problem that appears to affect grandparent caregivers overall well-being. The stress experienced by custodial grandparents was related to their caregiving situation, the subsequent environmental and socioeconomic status.
\end{abstract}

(C) 2018 The authors, under a Creative Commons Attribution-

NonCommercial 4.0

Corresponding author's email address: tselvi57@yahoo.com

Recommended citation: Pandialagappan, T., Ibrahim, R. Theories of Grandparental Stress. Journal of Business and Social Review in Emerging Economies, 4(1) 101-106

DOI: $10.26710 /$ jbsee.v4i1.372

\section{Introduction}

\section{Theories of Grandparental Stress}

Parenting second time around involves a change in lifestyle for most people and it's vitally important to take care of them mentally as well as physically. Becoming a caregiver to a grandchild can be both rewarding and stressful. Reasons for caring for the grandchildren vary depending on the caregiving situation. Grandparents raising their grandchildren may experience poorer physical and mental health, role overload, and isolation from peers due to parenting demands. Although it is not a new phenomenon, awareness of grandparental stress and interest in examining the problem are relatively new. Most studies on grandparent caregiver functioning have focused on the challenges and deficits of grandparent headed families. Little research has been conducted on the theoretical perspectives of grandparental stress. The goal of this article is to provide an overview of the theories might explain factors influencing grandparental stress.

\section{Theoretical Perspectives of Grandparental Stress}

This article attempts to theorize the causes of grandparental stress and why custodial grandparents are vulnerable to stress. Thus, theories from different disciplines, such as psychology, sociology, and biology, are presented to explain why grandparental stress occurs. 


\section{Social Exchange Theory}

Every relationship needs give and take, but the balance of this exchange will not necessarily be equal. The social exchange theory assumes that all human relationships are a matter of costs and rewards and people weigh the potential benefits and risks of social relationships to make a rational decision of whether or not to progress that relationship.

According to this theory, grandparental stress arises when grand parenting demands exceed the expected and actual resources available to the grandparents that permit them to succeed in their role. There are generally three categories of grandparents: non caregiving, co- parenting, and custodial. Custodial grandparents are the primary focus of this paper due to their caregiving responsibilities and increased risk for stress. Custodial grandparents are those who provide full time care for their grandchildren without the presence of biological parents. Outcome of raising a grandchild is referred as the combination of costs and rewards.

Raising children can be a physically demanding at any age, but grandparents may be affected more due to their age, lacking of energy and difficult circumstances. Common issues that grandparents report include loss of freedom due to caregiving responsibilities, experiencing parenting differently the second time around, complex family situations, marital dissatisfaction, lacking of self-care, ambivalence or resentment toward their adult child, emotional or behavior problems in their grandchildren, social isolation, declining physical health, and financial strains. Though grand parenting is traditionally seen as a blessing experience, the reality of being a custodial grandparent is not always positive. Thus, exchange theory posits that when custodial grandparents' burdens outweigh the rewards, they are more likely to experience stress.

\section{Role strain theory}

Strain is expressed as a feeling of frustration experienced by an individual, that stems from depletion of energy and resources required to fulfill social role expectations and obligations. The role strain perspective suggests that multiple roles can make individuals feel over exhausted, thereby having a harmful effect on well-being. According to the life stress paradigm, when role accumulation stressors wears down or overwhelms an individual's coping capacity, then it could be chronic source of stress that can negatively impact health. Painting a picture of grand parenting today is complicated.

Raising a second generation poses great challenges and requires major adjustments. "Off time" parenting responsibility can compromise grandparents' well-being and increase their risk of health decline, in addition to the added ambiguous nature of the caregiving role, conflict with spouse and family members, behavioral difficulties among grandchildren, limited financial resources, social isolation and lack of time for self-care. These demands on time, together with stresses from caregiving can be detrimental to grandparents' physical and mental health.

\section{Ecological system theory}

The ecological theory view human development and environment as inseparable components of a larger system. This theory argues that social environment and biology are intertwined in their influence on human. System within the social environment includes family, peers, community, sociocultural traditions and values which provides support for individual's development and health. From an ecological perspective, grandparents raising grandchildren are highly influenced by the quality of the environments within which they are embedded.

An enriching and stimulating environment with social support and resourcefulness, bolster grandparents' capacity to deal with caregiver stressors thereby improve their overall well-being. A problematic environment, by contrast, increase grandparents' vulnerability to stress and disparities in both mental and physical health. For example, grandparents who live in poverty, in conflict with family members, and lose connection with their social networks of friends may find it more stressful and difficult 
to cope with their caregiving responsibilities than grandparents in hassle free environment.

\section{Self-efficacy Theory}

Perceived self-efficacy refers to beliefs in one's capability to accomplish in specific tasks or situations that involve complex circumstances, ambiguous, unpredictable, stressful elements and survival pressures. These perceptions influence over people's ability to think, personal standards, emotional states, their aspiration and self-motivation. Self-efficacy develops out of early interactions between external experiences and self-perception. The basic principal behind this theory is positive life experiences with nurturing social environment enhances self-efficacy, while negative effects of life stressors such as loss of personal time, complex family situations, social isolation, declining physical health and financial difficulties serve to reduce self-efficacy. Based on self-efficacy theory, grandparents with strong sense of efficacy play an active role in the lives of their grandchildren and have a greater strategic flexibility in coping with caregiving demands.

However, grandparents with low self-efficacy have been associated with depression, anxiety, helplessness as well as negative effects in social and emotional relationships. Additionally, they may become overwhelmed when facing various stressors which might leads to negative outcomes that affect general well-being.

\section{Family adaptation theory}

Family adaptation is a fluid process in which the family members continually make adjustments, expend efforts to reduce and tolerate stress or conflict. When stress and demands outweigh strengths and resources, family adaptation is in jeopardy, and a family stress may develop. Though some stress is inevitable in the family unit, it becomes problematic when the degree of stress in the family system contributes to increased dysfunction. A family's level of adaptation often changes with a reappraisal of a situation within external and internal contexts.

Today grandparents are performing multiple dynamic roles within their families. Because grandparents who raise their grandchildren are confronted with unique stressors associated with parenting, adaptation appears to play an important role in exploring the demands of caregiving.

Factors that facilitate or hinder grandparents' adaptation process include: family strengths, tribulations of parenting for the second time, relationship and communication with family members, resources, selfcare and social support. Thus, adaptation theory posits that poor resources and inadequate support can be associated with lower grandparent role satisfaction and less tolerance in dealing with the stressors of raising their grandchildren. Additionally, if the duration of stressors is extended beyond the coping power of grandparents, they may become exhausted and may develop increased susceptibility to health problems.

\section{Symbolic Interaction Theory}

The symbolic interaction perspective focuses on how individuals use their behaviours and interaction with others as a basis for evaluating their own role performances. One of the most important contributions of symbolic interaction theory is the understanding that individuals are not just passive role players but actively strive to improve self-conceptions. Positive self-conceptions provide a set of intrinsic motives that increase individual behaviours and responses to roles. Symbolic interaction theory suggests that selfprocesses motivate grandparent identity meanings, centrality, and self-esteem to enhance their role satisfaction.

Factors influencing self-conception among custodial grandparents are age of the grandchildren, gender, emotional and physical hardships, poor health, financial resources, and socialization. In addition, nature of grandparent-grandchild relationship can also restricted by the negative attitude of parents toward grandparents. 
According to symbolic interaction theory, positive evaluation of grandparent role is directly associated with increased life satisfaction and reduced caregiver stress by providing greater sense of purpose in life, which enhances overall well-being of grandparents. Conversely, negative self-evaluation during grandparenthood has been correlated with diminished physical and mental health.

\section{Feminist Theory}

Feminist theory emphasize on analysing gender inequality and the role of women in the household. Therefore, grandparental stress can be defined as a feminist issue because there is ample evidence that women take on majority household responsibilities and grandparenting activities. As women are more likely to assume the caregiving role than men, grandparent caregivers are disproportionately represented by grandmothers. Thus burdens of custodial grandparenting expected to be more pronounced for grandmothers than grandfathers. Furthermore, women have greater difficulty with parenting second time around because they did not have adequate financial and societal support.

\section{Conclusion}

This review aimed to assess theories of grandparental stress. Several theories that might explain possible causes for grandparental stress were identified and discussed. Based on the reviewed theories, several factors including caregiver burdens outweigh the rewards (Social exchange theory), depletion of energy and resources to fulfil social role expectations (role strain theory), problematic environment (ecological system theory), reduced capability to manage complex circumstances (self-efficacy theory), less tolerance in dealing with the stressors (family adaptation theory), negative self-conception (symbolic interaction theory) gender of caregiver (feminist theory) cause grandparental stress. Hence, it can be concluded that grandparental stress is a multifactorial, complex problem that affects every aspect of grandparent caregivers' life. Because our review reveals that no single theory can virtually explain all causes of grandparental stress, developing an integrated theory with a comprehensive perspective is recommended.

\section{References}

Arber S, Ginn J. (1995). Connecting gender and ageing: A sociological approach. Philadelphia: Open University Press.

Bandura, A. (1997). Perceived self-efficacy: Exercise of control through self-belief. Controversial issues in behavior modification (pp. 27-59). Amsterdam: Swets \& Zeitlinger.

Boss, P. (2002). Family Stress Management: A Contextual Approach. Thousand Oaks, CA: Sage Publications. Bronfenbrenner, U. (1979). The ecology of human development. Cambridge, MA: Harvard University Press.

Gecas, V. (1989). The social psychology of self-efficacy. Annual Review of Sociology, 75, p. 291-316.

Gecas, V., \& Burke, P. J. (1995). Self and identity. In K. Cook, G. A. Fine, \& J. House (Eds.), Sociological perspectives on social psychology (pp. 41-67).

Goode WJ. (1960). A theory of role strain. American Sociological Review; 25: p. 483-496.

Hayslip, B., Kaminski, P. L. (2005). Grandparents raising their grandchildren: A review of the literature and suggestions for practice. The Gerontologist, 45: p. 262-269.

King, V., \& Elder, G. H., Jr. (1995). American children view their grandparents: Linked lives across three rural generations. Journal of Marriage and the Family, 57, p. 165-178.

McCubbin, H., \& Patterson, J. (1983). Family transitions: Adaptation to stress. In McCubbin, H., \& Figley, C. (Eds.), Stress and the Family Volume I: Coping with Normative Transitions. New York, NY: Brunner/Mazel.

Patterson, J. M. (2002,). Integrating family resilience and family stress theory. Journal of Marriage and Family, 64, p. 349-360.

Roberto, K. A., Allen, K. R., \& Blieszner, R. (2001). Grandfathers' perceptions and expectations of relationships with their adult grandchildren. Journal of Family Issues, 22, p. 407-426.

Ross MET, Aday L. (2006). Stress and coping in African American grandparents who are raising their grandchildren. Journal of Family Issues, 27: p.912-932. 
Szinovacz ME, DeViney S, Atkinson MP. (1999). Effects of surrogate parenting on grandparents' well-being. Journal of Gerontology: Social Sciences. 54B:S376-S388.

Stryker, S., \& Burke, P. J. (2000). The past, present, and future of identity theory. Social Psychology Quarterly, 63, p. 284-297.

Thibaut, J. W., \& Kelley, H. H. (1959). The social psychology of groups. New York: Wiley. 